\title{
THE DESIGN AND IMPLEMENTATION OF SUGAR-CANE INTELLIGENCE EXPERT SYSTEM BASED ON EOS/MODIS DATA INFERENCE MODEL
}

\author{
Zongkun Tan ${ }^{1,2, *}$, Meihua Ding ${ }^{1,2}$, Xin Yang ${ }^{1,2}$, Zhaorong $\mathrm{Ou}^{1,2}$, Yan $\mathrm{He}^{1,2}$, \\ Zhaomin Kuang ${ }^{1,2}$, Huilin Chen ${ }^{3}$, Xiaohua Mo ${ }^{4}$, Zhongyan Huang ${ }^{5}$ \\ ${ }^{1}$ Remote Sensing Application and Test Base of National Satellite Meteorology Centre, \\ Nanning, China, 530022 \\ ${ }^{2}$ GuangXi Institute of Meteorology, Nanning, China, 530022 \\ ${ }^{3}$ HaiNan Province Meteorological Administration, Haikou, China, 570203 \\ ${ }^{4}$ Zhangjiang City Meteorological Administration, Zhangjiang, China, 524001 \\ ${ }^{5}$ YunNan Province Meteorological Administration, Kunming, China, 650034 \\ * Corresponding author, Address: GuangXi Institute of Meteorology, Nanning, 530022, P. R. \\ China, Tel: +86-771-5875207, Fax: +86-771-5865594, Email: tanzongkun@163.com
}

Abstract: One of the major problems in the real time decision of agricultural intelligence expert system is how to be obtained the real time information of crops growth and its close relation environment data. As result, the extraction of crops planting areas and their spatial distribution and their growth variety, especially when the natural disaster arises, such as drought, its spatial distribution and crops suffer from harmful degree have become the extraordinary important factors of the real time decision in agricultural intelligence expert system.

In order to be obtained the real time information of crops growth and its close relation environment data. In the first place, this paper presents an automatic approach to the sugar-cane planting areas and its spatial distribution and growth and classification of drought extraction for mixed vegetation and hilly region, more cloud using moderate spatial resolution and high temporal resolution EOS/MODIS data around Guangxi province, south of China. Next, the framework and the method for knowledge expressing and inference mechanism of the real time decision of sugarcane intelligence expert system are proposed. Finally, the information of sugarcane planting area and

Tan, Z., Ding, M., Yang, X., Ou, Z., He, Y., Kuang, Z., Chen, H., Mo, X. and Huang, Z., 2008, in IFIP International Federation for Information Processing, Volume 259; Computer and Computing Technologies in Agriculture, Vol. 2; Daoliang Li; (Boston: Springer), pp. 1181-1191. 
sugarcane growth variety and sugar-cane drought distribution are carried out by using multi-phase EOS/MODIS data and weather forecast are used in the sugarcane intelligence expert system, the mechanism combines concern rectangle and inference based on the produce type inference, and makes good use of their advantages.

Keywords: RS, Sugarcane, Intelligence Expert System, Inference diagnosis, Real time decision

\section{INTRODUCTION}

Agricultural intelligence expert system is one of the pervasive and the persuasive of modern agricultural technology in recent decade, China. Till 2006 year, there are more than 200 agricultural intelligent systems have been used in 29 provinces and cities in China, which involved 25 kind species crops and domestic animal and birds and marine lives etc. Simulate model and the rule knowledge of produce have been using in agricultural intelligent expert system, the people who have based on the localization of the tradition idea and experience knowledge to solve the agricultural management problems for long time have been broken. However, the agricultural management is an extraordinary complex system, which is impacted by climatic and soil and other biology, as well as manpower inference and interaction between individual and colony of biology. In addition, the agricultural management is faced the biology organism which growth with time change. Consequently, the integrity and reliability of model capability and the construct level of expert knowledge database contribution directly influence on the whole of capability of agricultural intelligent expert system. The integrity and reliability and real timely and of completely agricultural base database, especial the foresee of the environment factors variety of corps growth, which have become the key factor of deciding the agricultural intelligent expert system whether provide real time serves. These days, however, the agricultural expert systems of implementation in Guangxi province have had lack the decision capability of according crops growth and environment factors variety, because the information of the real time environment data and the information of crops growth are difficult to be obtained.

In view of Guangxi province is the biggest region of sugar-cane planting in China, and the sugar is extraordinary important material in our country. In this paper, Guangxi province in southern China was selected as the study 
area. The objectives of this research were to: (1) find out the way of identify and extraction of sugar-cane planting spatial distribution information in hilly, mixture vegetation and cloudy in southern, China; and (2) the retrieve a suitable monitor model for sugar-cane growth and drought based on EOS/MODIS data, and validate the model with estimated sugar-cane planting areas and the model with forecasted annual yield based on remote sensing; and (3) set up the model of sugar-cane intelligence expert system based on EOS/MODIS data.

\section{METHODS}

\subsection{Study area}

The study area is located in Guangxi province, south of China. It latitude is $20^{\circ} 54^{\prime}-26^{\circ} 23^{\prime} \mathrm{N}$ and longitude is $104^{\circ} 29^{\prime}-112^{\circ} 04^{\prime} \mathrm{E}$. Its total area is $236700.0 \mathrm{~km}^{2}$. It belongs to monsoon region of south subtropical zone and north tropical zone without four clearly demarcated seasons of spring, summer, autumn and winter. The climate here is hot and humid in summer and warm and dry in winter. In 2006/2007 year crushing season, sugar-cane planting area approach $853000 \mathrm{hm}^{2}$, the yield of sugar over $7.08 \times 10^{9} \mathrm{KG}$ in Guangxi province, which sugar yield approach $65 \%$ of the whole country.

\subsection{Data acquisition}

In this paper, EOS/MODIS imageries obtained from on December 1, 2002 to on December 31, 2006 were required; whose path/row is 1151/1230. When the data were obtained, more than one county without cloud or little cloud images were selected, then they were synthesized one or more images in the same month.

\subsection{Methods}

Due to the relationship between vegetation indices calculated by different algorithms, reflectance of bands and field measurements of NDVI, we can retrieve NDVI using EOS/MODIS data. With this relationship, a NDVI retrieval model for study area can be established. A specific flow chart of retrieval technique is shown as Fig. 1. 


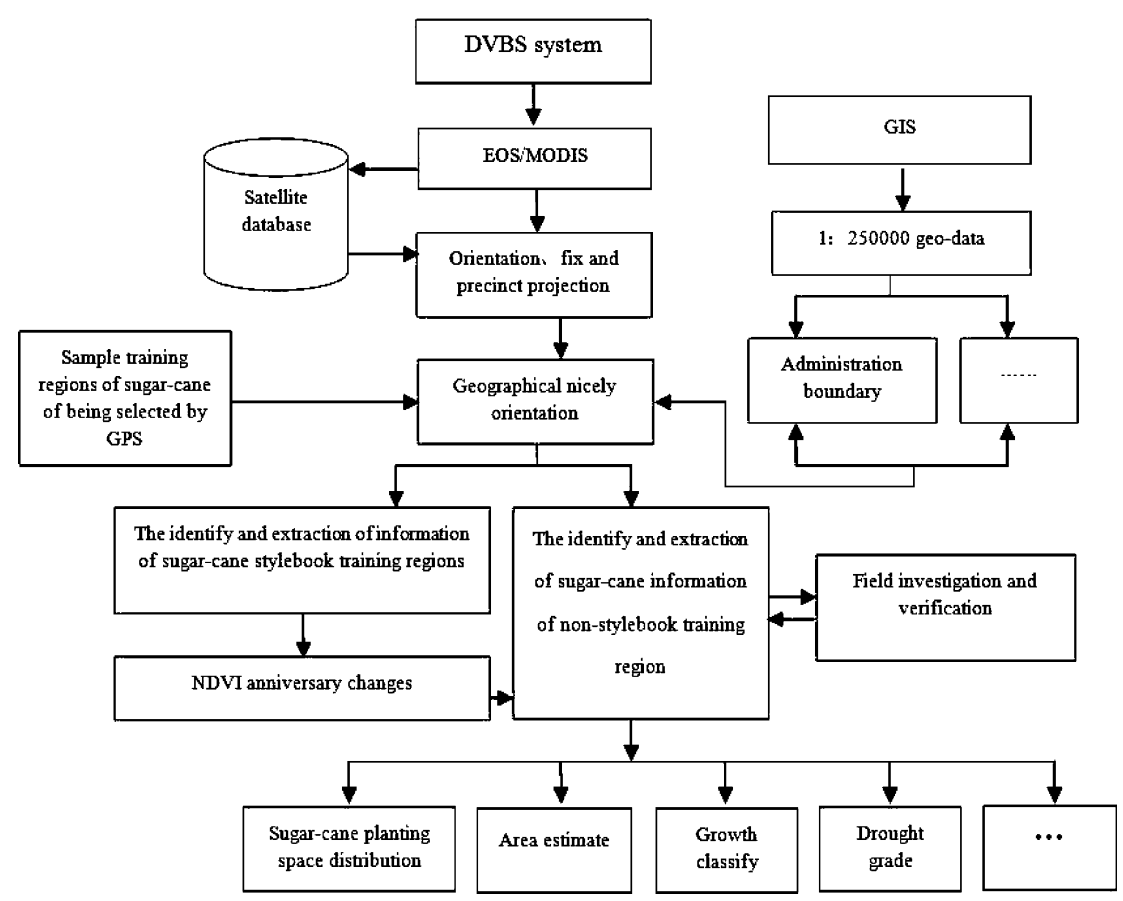

Fig. 1. The flow chart of the identify and extraction of sugar-cane planting space distribute information based on EOS/MODIS data

Based on the above flow chart of technique, detailed steps are described as follows:

\section{Inversing reflectance for EOS/MODIS imagery}

The objective of atmospheric correction for EOS/MODIS data is to attain related parameters which can indicate the vegetation inherent properties of the region. Since the remotely sensed image was affected by reflective solar energy, solar elevation, zenith angle, the thickness of aerosol and the bidirectional scattering due to the mutual influence of ground environment factors, we should take into account both atmospheric and bidirectional scattering to obtain accurate ground reflectance. Because the parameters of atmospheric profile based on measurements data or standard atmospheric profile were not established in China, in this paper we adopted international standard parameters of atmospheric profile to correct EOS/MODIS image.

\section{Obtaining characteristic parameters of vegetation}

Due to the chlorophyll and inner architecture of foliage, a special reflective spectrum of vegetation foliage was formed like intensive absorption in the red waveband and intensive reflection in the near infrared waveband. By the reflectance difference varied in the red and the near infrared waveband, we can calculate related parameters that indicate the 
conditions of vegetated surfaces, such as normalized difference vegetation index (NDVI) which is a simple, effective and experiential measurement to vegetation activity. To some extent, NDVI indicates the vegetation information of status and succession.

NDVI, a parameter (range -1-1) denoting the ground vegetation coverage can be derived from the reflectance in the red and the near-infrared wavebands. This equation reads:

$$
\text { NDVI }=\frac{\rho N I R-\rho R}{\rho N I R+\rho R}
$$

From the equation we can see that in the water area and roadway area and city or town area, theirs value of NDVI are below 0 or approach constant value in different seasons. But for the land surface with cover foliage, NDVI ranges from 0.1 to 0.7 . NDVI has been applied in many fields, such as land cover or change, vegetation and environment change, net primary productivity and the assessment of crop yield.

\section{Sample training regions of sugar-cane of being selected by GPS}

To the same foliage, its value of NDVI is various with its growth process. As result, the values of NDVI between foliages are diversity in different seasons. In order to mastery the spectrum characteristic of sugar-cane and distinguish sugar-cane from many kinds of foliages, some sample training regions of sugar-cane (the area must be bigger than $7 \mathrm{hm}^{2}$ ) in different county of Guangxi were selected by GPS (the Global Positioning System).

\section{The identify and extraction of sugar-cane planting information based on EOS/MODIS data}

In the first place, the values of NDVI of sample training regions of sugarcane during the main growing seasons were calculated. As result, we could find the variety trend of curves of sugar-cane in different regions being consistent (Fig. 2).

For the sugar-cane, its growth lasting more 8 to 12 months, and the main of crops is sugar-cane in Guangxi province during winter, and the areas of sugar-cane cover are reduced during crush season. When the crush season was over, the values of sugar-cane planting areas approached 0 . 


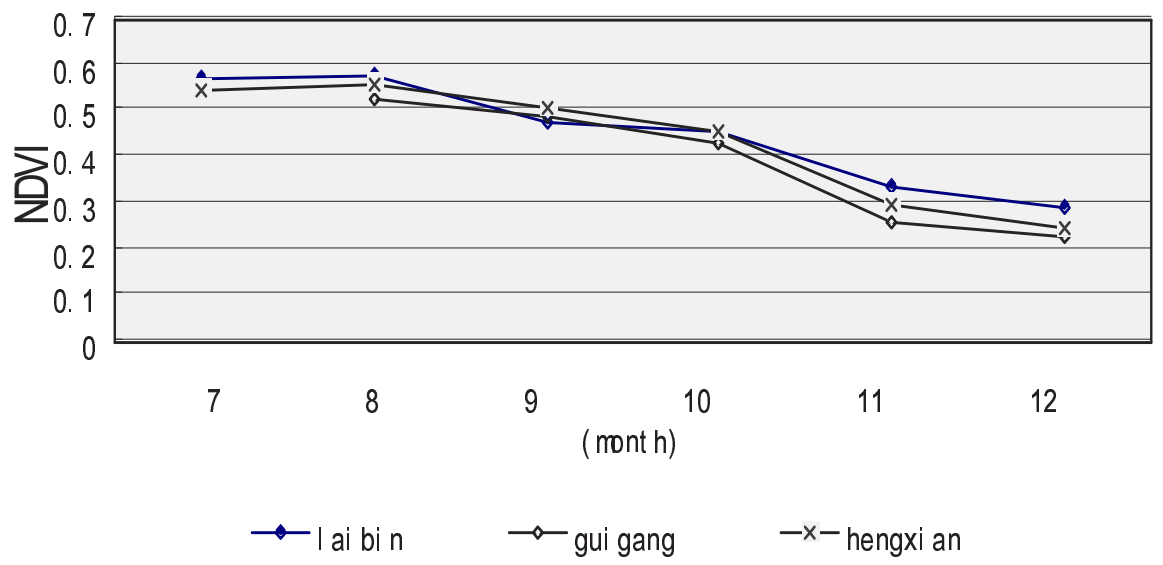

Fig. 2. The curse of NDVI of sugar-cane in different regions

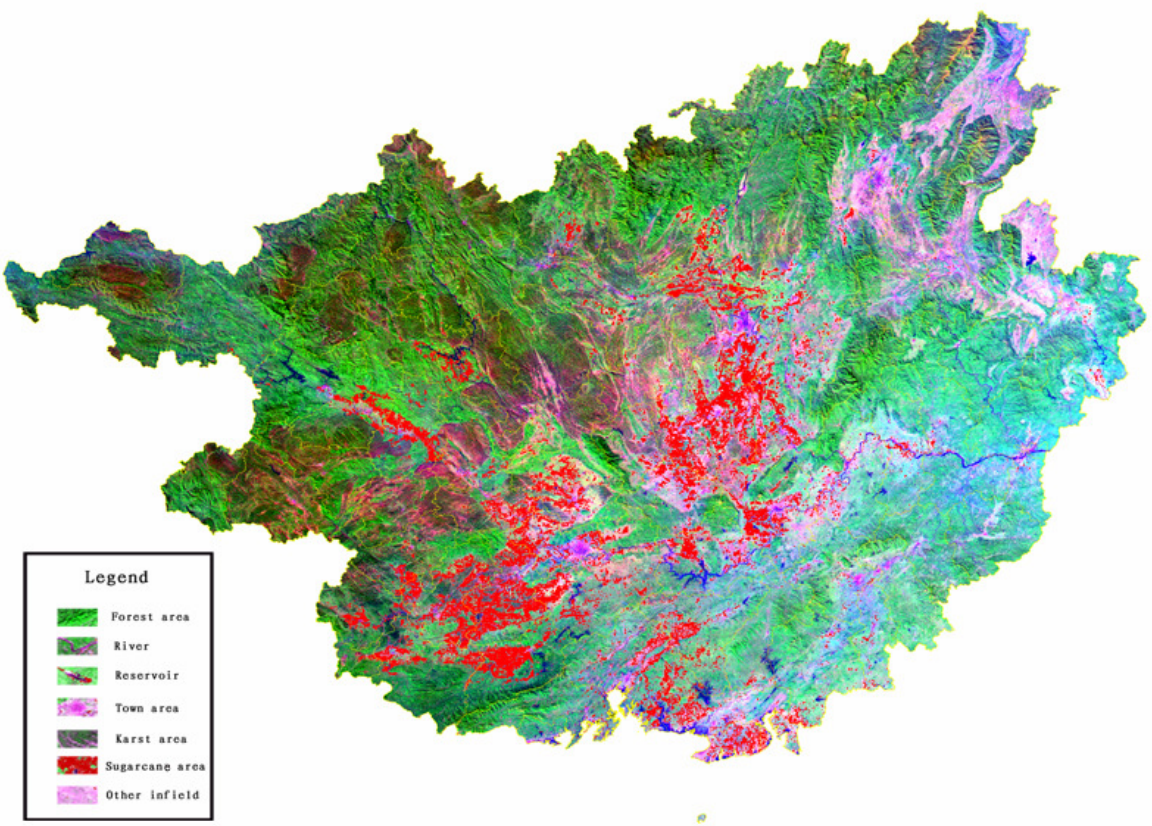

Fig. 3. The imagine of sugar-cane planting and its spatial distribution based on EOS/MODIS in Guangxi province, 2006

And the same time, corn and rice and soybean, theirs growth (from sowing to harvest) are general lasting 3 or 4 months. The south subtropical zone and north tropical zone forest growth lasting more than 12 months, but 
its value of NDVI anniversary approach constant. Consequently, the curves of NDVI variety in different foliages during the main growth seasons are difference. We can use the Maximum likelihood to extract the information of sugar-cane planting and its spatial distribution through the calculation of multiple-phase MODIS-NDVI from different foliages in Guangxi province. The result shows that the information of sugar-cane planting and its spatial distribution in 2006 were clearly in remote sensing imagine (fig. 3). The survey of field also showed that the information of sugar-cane planting based on multiple-phase EOS/MODIS data was highly reliable and truth.

\section{THE FRAMEWORK AND FUNCTION OF SUGAR-CANE INTELLIGENCE EXPERT SYSTEM BASED ON RS}

Compare with other agricultural intelligence expert system, the sugar-cane intelligence expert system based on RS certain consists of following sects: User connects and server and inference diagnosis and expert's knowledge database and environment database, which close relate sugar-cane growth and development, such as weather and water and soil and fertilize etc. it must be point out that the crop growth simulation model in agricultural expert system is replaced by the information of sugar-cane monitoring based on remote sense. Its flow chart as Fig. 4.

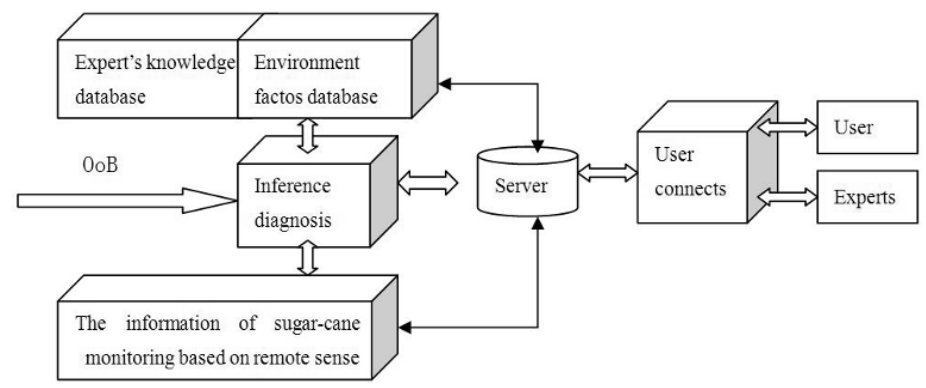

Fig. 4. The framework of the sugar-cane intelligent expert system based on RS

\section{SUGAR-CANE EXPERT'S KNOWLEDGE EXPRESS BASED ON RS}

According the value of sugar-cane NDVI and its yield data and field survey in different years, the growth of sugar-cane was divided by four steps: bad and average and good and better, which remarked for $\mathrm{GG}=\{\mathrm{G} 01$, 
G02, G03, G04\}. At the same time, the majority disasters which affect on sugar-cane yield and sugar yield, such drought and frost, were remarked for $\mathrm{ZZ}=\{\mathrm{Z} 01, \mathrm{Z} 02, \mathrm{Z} 03, \ldots\}$. The losing degree which were caused by nature disasters was divided by light and middle and severity and extremely: $\mathrm{FF}=\{\mathrm{F} 01, \mathrm{~F} 02, \mathrm{~F} 03, \mathrm{~F} 04\}$. In addition, the disasters from occur to die out were divided by arise and continue and aggravate and relax and relieve, its remarked for $\mathrm{XX}=\{\mathrm{X} 01, \mathrm{X} 02, \mathrm{X} 03, \mathrm{X} 04, \mathrm{X} 05\}$.

Since sugar-cane certain planting in dry land without irrigation in our country, the yield and sugar contain of sugar-cane are close relation with weather condition, especial the precipitation total and its distribution in different months. As result, the weather data and weather forecast information must be imported when we are constructing expert knowledge rules. The climatic factors estimated index as following:

$$
\begin{array}{ll}
\leq \bar{x} \mathrm{i}-2 \delta \mathrm{i} & \text { lower (less) } \\
(\overline{\mathrm{x}} \mathrm{i}-2 \delta \mathrm{i}, \overline{\mathrm{x}} \mathrm{i}-0.5 \delta \mathrm{i}) & \text { low (little) } \\
(\overline{\mathrm{x}} \mathrm{i}-0.5 \delta \mathrm{i}, \overline{\mathrm{x}} \mathrm{i}+0.5 \delta \mathrm{i}) & \text { average } \\
\overline{(\mathrm{x} i}+0.5 \delta \mathrm{i}, \quad \overline{\mathrm{x}} \mathrm{i}+2 \delta \mathrm{i}) & \text { high (much) } \\
\geq \mathrm{xi}+2 \delta \mathrm{i} & \text { higher (more) }
\end{array}
$$

In demand side,

$x i$ is the value of a period of ten days average in many years of climatic factor.

$\delta \mathrm{i}$ is the mean square error of the climatic factor historical data list.

In the first place, the classification of mean temperature (TM) and mean top temperature (TTM) and mean lowness temperature (LTM) and total of precipitation (PT) and total of solar (ST) of a period of ten days were expressed with Set. For instance, the classification of mean temperature is expressed with Set: $\mathrm{TM}=\{\mathrm{TM} 01, \mathrm{TM} 02, \mathrm{TM} 03, \mathrm{TM} 04, \mathrm{TM} 05\}$. In demand side, TM01 is lower, TM02 is low, TM03 is normal, TM04 is high, TM05 is higher.

In common, the classification of the factors of weather cast was expressed with Set. As result, the formula set of the situation of weather in past and weather forecast in future was expressed: TM $\cap \mathrm{TTM} \cap \mathrm{LTM} \cap \mathrm{PT} \cap \mathrm{ST} \cap$ $\mathrm{TF} \cap \mathrm{TTF} \cap \mathrm{LTF} \cap \mathrm{PF} \cap \mathrm{SF}$.

From what has been discussed above, the weather and climate survey in past years and the information of sugar-cane remote sensing monitor were synthesis, the corresponding agricultural management rules have been formed requirement of service object. 


\section{THE INFERENCE MECHANISM OF SUGAR-CANE INTELLIGENCE EXPERT SYSTEM BASED ON RS}

The inference mechanism of sugar-cane intelligence expert system based on RS was equally following the principle of the disaster first. The management of agriculture or enterprise should adopt the measure of avoid and Anti- and relief disaster, and could take no account of the influence of the other factor when the monitoring the sugar-cane have already suffered the influence of different degree disaster or the disaster will arise forecast. Its inference process as follows:

(1) The user was distinguished first when he or she entered the sugar-cane intelligence expert system, and the system demanded the user to choose sugar-cane region which he or she concerned.

(2) According to the user's choice, the system will automatically link the data of sugar-cane remote sensing monitoring and will show that the newest imagine of sugar-cane remote sensing monitoring whether surfer the disaster which the region of the user chose. The system will give the conclusion of anti- and relief measures from the expert knowledge database to the user when the disaster arises.

(3) The system indexes the data of weather forecast information and choices the latest forecast information of region where the user chose, and judgment the disaster emergence or not. If the disaster emergence, the system will give the conclusion of the disaster prevention, reduce the disaster for user.

\section{THE REALIZATION OF THE REAL TIME DECISION FUNCTION OF SUGAR-CANE INTELLIGENCE EXPERT SYSTEM BASED ON RS}

The influence sugar cane grows the growth's disaster from take place to die out could mean with following relation: XX.RZ. In demand side,

Light degree Middle degree Severity degree Extremity degree

$$
\begin{aligned}
& \mathrm{RZ}=\left[\begin{array}{cccc}
\text { Z1F01 } & \text { Z1F02 } & \text { Z1F03 } & \text { Z1F04 } \\
\text { Z2F01 } & \text { Z2F02 } & \text { Z2F03 } & \text { Z2F04 } \\
\text { Z3F01 } & \text { Z3F02 } & \text { Z3F03 } & \text { Z3F04 }
\end{array}\right] \\
& X X=\{X 01, X 02, X 03, X 04, X 05\}
\end{aligned}
$$




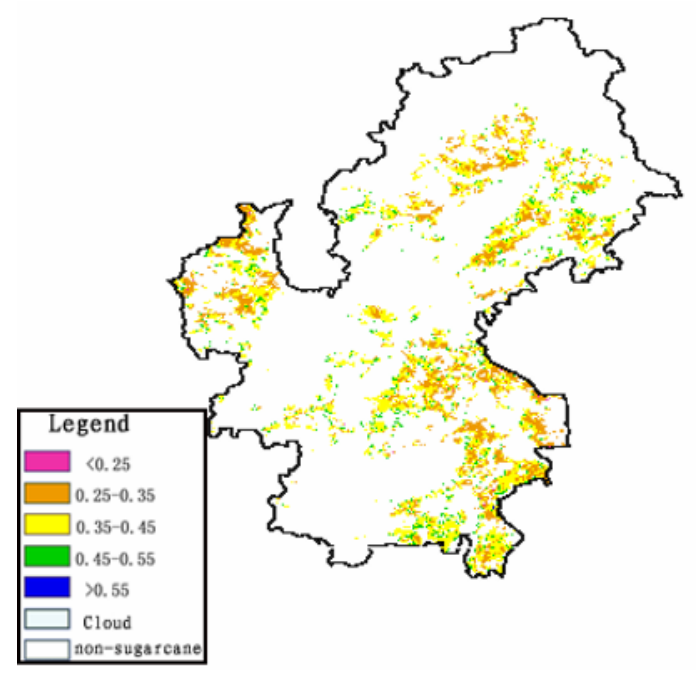

Fig. 5. The sugar-cane drought classification in Congzuo city of Guangxi province, China. Oct, 2006

Fig. 5 is the image of remote sensing which the sugar-cane drought classification and distribution in Congzuo city of Guangxi province, Oct, 2006. For the whole city, we could find that the drought degree was diversity in different villages. There for, the villages of minimum administration district were carved up in imagine of remote sensing in order to the sugarcane intelligent system could identify the information of sugar-cane. In the nature village, we regulated the most of pixels which suffer the same disaster grade to representative the whole village suffer disaster status, and its values of disaster grade was set 1 , and the rest grade was set 0 . Because of weather disaster grade forecast is only, if the result of forecast shows that the disaster would arise, its result of forecast will be set 1, if the result of forecast shows that the disaster would not arise, its result of forecast will be set 0 . So we could calculate out the value of XX'RZ. According to the expert knowledge databases and identify the code, the system would give out the accurate diagnosis conclusion immediately to user.

\section{CONCLUSIONS AND DISCUSSIONS}

Based on the above study and analysis, some conclusions can be drawn as follows:

(1) It is an effective way to extraction of sugar-cane planting spatial distribute information by taking some sample training regions of sugar-cane in different county. 
(2) The information of sugarcane planting area and sugarcane growth variety and sugar-cane drought distribution are carried out by using multiphase EOS/MODIS data and weather forecast are used in the sugarcane intelligence expert system, the mechanism combines concern rectangle and inference based on the produce type inference, and makes good use of their advantages.

\section{ACKNOWLEDGEMENTS}

This study has been funded by China National 863 Plans Projects (Contract Number: 2001AA115360), It is also supported by the China Meteorological Administration new technology extend project (Contract Number: CMATG2006M42), Sincerely thanks are also due to Guangxi Climate center and National Satellite Meteorology Center for providing the data for this study.

\section{REFERENCES}

Cheng Qian, Huang J F. 2003. Analyses of the correlation between rice LAI and simulated MODIS vegetation indices, Red Edge Position [J]. Transactions of the CSAE, 19(5):104108.

Yang Bangjie, Pei Zhiyuan, Zhang Songling. 2001. RS-GIS GPS-based agriculture condition monitoring systems at a national scale [J]. Transactions of the CSAE, 17(1):154-158.

Kontoes C, Wilkinson G G, Burril A. et al. 1993. An Experimental System for the Integration of GIS Data in Knowledge Based Image Analysis for Remote Sensing of Agriculture [J]. International Journal of Geographical Information Systems, 7(3):247-262.

Murthy C S, Raju P V, Badrinath K V S. 2003. Classification of Wheat Crop with Multitemporal Images: Performance of Maximum Likelihood and Artificial Neural Networks [J]. INT. J. Remote Sensing, 24(23):4871-4890.

Zhao M S, Fu C B, Yan X D et al. 2001. Study on the relationship between different ecosystem and climate in China using NOAA/AVHRR data. Acta Geographica Sinica, 56(3):287-296. (in Chinese)

Zheng Y R, Zhou G S. 2002. A forest vegetation NPP model based on NDVI. Acta Phytoecologica Sinica, 24:9-12. (in Chinese) 